\title{
BMJ Open Body mass, cardiovascular risk and metabolic characteristics of young persons presenting for mental healthcare in Sydney, Australia
}

\author{
Elizabeth M Scott, Daniel F Hermens, Django White, Sharon L Naismith, \\ Jeanne GeHue, Bradley G Whitwell, Nick Glozier, Ian B Hickie
}

To cite: Scott EM,

Hermens DF, White D, et al. Body mass, cardiovascular risk and metabolic characteristics of young persons presenting for mental healthcare in Sydney, Australia. BMJ Open 2015;5: e007066. doi:10.1136/ bmjopen-2014-007066

- Prepublication history for this paper is available online. To view these files please visit the journal online (http://dx.doi.org/10.1136/ bmjopen-2014-007066).

Received 31 October 2014 Revised 17 February 2015 Accepted 2 March 2015

CrossMark

Clinical Research Unit, Brain \& Mind Research Institute, University of Sydney, Camperdown, New South Wales, Australia

Correspondence to Professor Ian B Hickie; ian.hickie@sydney.edu.au

\section{ABSTRACT}

Objectives: To determine the body mass, cardiovascular and metabolic characteristics of young people presenting for mental healthcare.

Design: Cross-sectional assessments of body mass, cardiovascular and metabolic risk factors.

Setting: Two primary-care based sites in Sydney, Australia for young people in the early stages of mental disorders.

Participants: A clinical sample of young people (12-30 years) with mental health problems.

Outcome measures: Daily smoking rates, body mass index (BMI), blood glucose and lipids, blood pressure (BP) and pulse rate.

Results: Of 1005 young people who had their BMI determined ( $62 \%$ female; $19.0 \pm 3.5$ years), three quarters $(739 / 1005)$ also had BP recordings and onethird (298/1005) had blood sampling. Clinically, 775 were assigned to one of three diagnostic categories (anxious-depression: $n=541$; mania-fatigue, $n=104$; developmental-psychotic $n=130$ ). The profile of BMI categories approximated that of the comparable segments of the Australian population. Older age, lower levels of social functioning and higher systolic BP were all associated with high BMI. In a subset $(n=129)$, current use of any psychotropic medication was associated $(p<0.05)$ with increased BMI. Almost onethird of cases were current daily smokers (compared to population rate of $11 \%$ ). Males had a higher proportion of raised glucose and high-density lipoprotein (HDL) compared to females $(9.3 \%$ and $34.1 \%$ vs $2.1 \%$ and $5.9 \%$, respectively). Overall, there was no relationship between BMI and fasting glucose but significant relationships with triglycerides and HDL were noted. Furthermore, there were no significant relationships between diagnostic subgroup and metabolic profiles.

Conclusions: Daily smoking rates are increased among young people presenting for mental healthcare. However, these young people do not demonstrate adverse cardiometabolic profiles. The high levels of smoking, and association of BMI with adverse social circumstances, suggest that risk factors for chronic disease are already present and likely to be compounded by medication and social disadvantage.

\section{Strengths and limitations of this study}

- A cross-sectional study of a large number of young persons with emerging mental disorders seeking primary-care based health services.

- The findings in this younger age group, early in the course of care, are substantially different from those with established mental disorders.

- While evidence for a possible relationship between exposure to medication and being overweight or obese was detected, a larger sample and a longitudinal design are required to elaborate the nature of this cross-sectional relationship.

- The study results suggest that a populationhealth focused strategy is required to prevent the onset of metabolic or cardiovascular disorders.

\section{INTRODUCTION}

There is international recognition of the premature death and disability attributable to mental disorders-reflecting their early ageof-onset, high population prevalence, chronicity and comorbidity with physical illness. ${ }^{12}$ Much of the increased risk to premature death that is not accounted for by suicide or other accident or injury is due to premature cardiovascular disease. ${ }^{3} 4$ To reduce total illness burden due to mental disorders, active primary and secondary risk reduction, earlier identification of disorder and enhanced longterm care are now recognised international priorities. ${ }^{15-9}$

While the reduction in premature death or ongoing disability directly attributable to mental ill-health has been emphasised, ${ }^{10-12}$ far less focus has been directed towards development of early interventions to reduce poor physical health outcomes. This is despite strong evidence of increased rates of all-cause mortality, and, most notably, increased rates of premature cardiovascular morbidity. ${ }^{13} 14$ The pathways to increased cardiovascular 
disease are complex. Among those with established mental disorders these include: increased exposure to known risk factors (eg, smoking, obesity, low physical activity); less active management of other risk factors (eg, glucose intolerance, dyslipidaemia, hypertension); and, the adverse impacts of other intrinsic factors (eg, disturbed circadian rhythm; perturbed sympathetic and parasympathetic nervous system regulation or increased chronic inflammation). ${ }^{15-18}$ Of additional concern is the potential adverse effects of early or continued exposure to medical treatments (eg, second generation antipsychotics, some antidepressants) that may impart increased risk of obesity, glucose intolerance or a broader metabolic syndrome.

Internationally, there has been increasing focus on the increasing rates of being overweight or obese among young people, particularly those living in developed countries. The pathways linking these changes in body mass in childhood and premature cardiovascular disease in adulthood are themselves complex. They are likely to include direct effects of childhood or teenage obesity on the early development of glucose intolerance, hypertension, dyslipidaemia or chronic inflammation as well as the indirect effects of predisposing the young person to obesity as an adult. ${ }^{19}$ Importantly, such pathways are not inevitable and lend themselves to the development of active intervention strategies, particularly during the adolescent or early adult period.

By contrast with evidence from middle-aged persons with established psychotic or mood disorders of increased rates of smoking, obesity, hypertension, other vascular risks or impaired metabolic parameters, ${ }^{16-18} 20$ there is little data describing these same parameters in large numbers of young people presenting for mental healthcare with common anxiety or mood disorders. Further, there is relatively little information available exploring the potential links between the nature of the mental disorder (eg, depressive subtypes, psychotic disorder) or the stage of illness ${ }^{21} 7$ and the pattern of risk factors evident. Therefore, in the context of developing new and enhanced primary-care based mental health services for young people in the early phases of major disorders ${ }^{22} 23$ we are examining the rates of altered body mass, cardiovascular function and glucose and lipid profiles and studying cross-sectional and longitudinal patterns of association with illness type, duration and exposure to other treatments.

\section{METHODS}

Participants (aged 12-30 years) were recruited from either the headspace Campbelltown (outer suburban, South Western Sydney) or Camperdown (inner urban; co-located with the Brain \& Mind Research Institute) site. These young people were referred by general practitioners (GPs), paediatricians, schools, welfare agencies, family/friends or they were self-referred. All participants gave prospective written informed consent for their clinical data to be used for research purposes. Parental consent was obtained for participants under 18 years of age.

\section{Measures}

Part clinical information was obtained via: (1) a brief selfreport questionnaire and/or (2) a clinical assessment. Detailed methods have been set out previously. ${ }^{84-26}$ On presentation to the headspace site, participants were weighed and measured (in height) to ascertain their body mass index (BMI). In addition, blood pressure (BP) was taken by a health professional as part of their routine assessment and pathology requests were made by the referring clinician (ie, IH, ES or headspace GP) to obtain the following standard laboratory lipid values: low-density lipoprotein (LDL), high-density lipoprotein (HDL), cholesterol (CHOL) and triglyceride (TG). Fasting glucose $>5.5 \mathrm{mmol} / \mathrm{L}$ was considered 'impaired' as recommended by an American Diabetes Association (ADA) expert committee. ${ }^{27} 28$

\section{Allocation to clinical subtypes}

An independent reviewer (DFH) allocated cases to one of the three proposed subgroups ${ }^{23}$ on the basis of the description of the clinical presentation alone. Any cases presenting with depressive symptoms only, with no evidence of psychotic or manic features and no indication of atypical symptoms were allocated to the anxiousdepression (ANX-DEP) group. The developmentalpsychotic (DEV-PSY) group is hypothesised to be associated with autism, schizophrenia and/or psychotic phenomena. ${ }^{29-32}$ Any cases with manic-like symptoms (manic, hypomanic or brief hypomanic phenomena) are preferentially allocated to the mania-fatigue (MAN-FAT) subtype irrespective of past or current evidence of psychotic or other phenomena. We employ the fatigue (FAT) label as the individual characteristics that most frequently differentiate the trajectories as the atypical features of depression, especially reduced activation and energy, and increased need for sleep, etc. ${ }^{33-35}$ The revised Diagnostic and Statistical Manual of Mental Disorders, fifth edition (DSM-V) criteria recognise the importance of activation as a cardinal feature of bipolarity, which is often a manifestation of underlying circadian rhythm dysregulation. ${ }^{36} 37$ The final (and here residual) subtype comprises individuals who frequently reported childhood anxiety, but later show evidence of heightened stress-sensitivity and an evolving depressive disorder (but without evidence of a 'fatigue' profile); this is the ANX-DEP subtype. ${ }^{22}$

\section{Data reduction}

As a means to compare data to the general population, participants were collapsed into the following age groups-depending on the measure of interest. For BMI we used the same age-bands as those employed in the 2007-2008 National Health Survey: ${ }^{38}$ (1) 12-15 years; (2) 16-17 years; and (3) 18-24 years. For the comparison of nicotine (tobacco) use we used the categories of 
the 2010 National Drug Strategy Household Survey: ${ }^{13}$ (1) 12-17 years; (2) 18-19 years; and (3) 20-30 years.

\section{Statistical analyses}

Statistical analyses were performed using the Statistical Package for Social Sciences (SPSS V.21, IBM Corp). Group differences in demographic, clinical and metabolic variables were assessed via t test, analysis of variance (ANOVA) or $\chi^{2}$ tests where relevant. If homogeneity of variance was violated (eg, according to Levene's test) the corrected degrees of freedom and $p$ values were calculated using Welch's correction. To analyse the relationships between metabolic variables (BMI, fasting glucose, total cholesterol, BP, pulse rate) and demographics (sex, age), socio-occupational functioning (Social and Occupational Functioning Assessment Scale, SOFAS), psychological distress (K-10), and smoking status we performed multiple linear regression (MLR) analyses utilising the 'enter' method. All analyses were two tailed and employed an $\alpha$ level of 0.05 .

\section{RESULTS}

Inclusion in this sample has been determined by presence of a recording of BMI in participants between the ages of 12 and 30 years (median age $=19.0$ years; mean age $=19.0$ years; $\mathrm{SD}=3.5$ years). As the number of other cardiovascular or metabolic risk factors recorded in these participants varied, the results are presented in order of completeness of data.

\section{Body mass index}

BMI recordings were available for 1005 individuals, including $62 \%$ females $(\mathrm{n}=625$, mean age $=18.9 \pm 3.5$ years $)$ and $38 \%$ males $(\mathrm{n}=380$, mean age $=19.2 \pm 3.6$ years $)$. There was no significant difference in BMI between females (23.6 $\pm 5.7)$ and males $(24.0 \pm 5.5) ;(t(1003)=-1.2, p=0.755)$. Both females and males showed a small but significant correlation between older age and higher BMI $(\mathrm{r}=0.147, \mathrm{n}=625$, $\mathrm{p}<0.001 ; \mathrm{r}=0.113, \mathrm{n}=380, \mathrm{p}<0.05$; respectively). With regards to the distribution of cases across BMI categories within each gender, there was a higher proportion of males $(37.1 \% ; 141 / 380$ vs females: $30.2 \%$; $189 / 625)$ in the overweight/obese category and a higher proportion of females in the normal (females: $59.8 \%$ vs males: $55.8 \%$ ) and underweight (females: $9.9 \%$ vs males: $7.1 \%$ ) categories. The overall $\chi^{2}$ test for this crosstab (cases within each gender by BMI category) was significant $\left(\chi^{2}(1005)=6.2\right.$, $\mathrm{p}=0.046$ ).

We tested for differences in other demographic, clinical and cardiovascular risk characteristics across these BMI categories (table 1). Notably, current social and occupational function (SOFAS) was most impaired in those who were overweight or obese. For the set of demographic and clinical predictors of BMI examined, linear regression analyses demonstrated only two significant predictors-namely age $(\beta=0.144, p<0.01)$ and SOFAS $(\beta=-0.134, p<0.05)$ with the overall model $(\mathrm{F}(5,379)=3.6, \quad \mathrm{p}<0.005)$ explaining only $4.6 \%$ of the variance (adjusted $\mathrm{R}^{2}=0.033$ ).

Figure 1 shows the proportions of cases within the BMI categories in our youth mental health sample ('YMH') as compared to their age-matched peers in the Australian general population. ${ }^{38}$ Among these comparisons, there are two notable differences: (1) YMH had a smaller proportion of 12-15-year-olds in the 'underweight/normal' group compared to the general population $(62.6 \%$ vs $73.2 \%$; figure 1); and (2) YMH sample had a smaller proportion of overweight 18-24-year-olds compared to the general population $(18.7 \%$ vs $25.1 \%$; figure 1).

Current medication status was available for a subset $(\mathrm{N}=129)$ of individuals, of whom, $65.9 \%(\mathrm{~N}=85)$ were underweight or normal weight and $34.1 \%(\mathrm{~N}=44)$ were overweight or obese. These two groups (ie, underweight/normal weight vs overweight/obese) were significantly $(\mathrm{p}<0.001)$ different in age $(19.1 \pm 3.8$ years vs $21.2 \pm 4.1$ years, respectively) but they did not differ in the proportion of each gender $(70.6 \%$ vs $59.1 \%$ females, respectively). Thus, $2 \times 2 \times 2 \quad \chi^{2}$ analyses were conducted to determine whether the major BMI groups differed in medication status while controlling for age (as a categorical variable: $12-19$ vs 2030 years). For nil versus 'any psychotropic medication' the overall (ie, $2 \times 2)$ model was significant $\left(\chi^{2}(1,129)\right.$ $=5.3, \mathrm{p}=.024)$, whereby $84.1 \%$ of those in the overweight/obese category were currently medicated,

Table 1 Demographic, clinical and blood pressure values for (1) underweight; (2) normal; (3) overweight/obese cases aged $12-30$ years $(\mathrm{N}=1005)$

\begin{tabular}{|c|c|c|c|c|}
\hline & Under $(n=89)$ & Normal $(n=586)$ & Over/obese $(n=330)$ & $\begin{array}{l}\text { Significance test } \\
\chi^{2} \text { or ANOVA (df) [p] }\end{array}$ \\
\hline Female, \% (n) & $69.7 \%(n=62)$ & $63.8 \%(n=374)$ & $57.3 \%(n=189)$ & $\chi^{2}(1005)=6.2[0.046]$ \\
\hline Age in years (mean $\pm S D$ ) & $18.7 \pm 2.9$ & $19.0 \pm 3.4$ & $19.1 \pm 3.9$ & $F(252.7)=0.7[0.487]$ \\
\hline SOFAS & $65.8 \pm 11.1$ & $65.1 \pm 11.7$ & $61.2 \pm 11.9$ & $F(753)=9.8[0.000]$ \\
\hline Distress (K-10 total) & $30.3 \pm 9.0$ & $30.3 \pm 8.6$ & $29.6 \pm 8.7$ & $F(670)=0.5[0.589]$ \\
\hline Current smoker, \% (n) & $24.0 \%$ & $34.5 \%$ & $22.3 \%$ & $\chi^{2}(659)=10.7[0.005]$ \\
\hline Pulse rate & $75.8 \pm 15.8$ & $75.2 \pm 18.0$ & $78.9 \pm 16.5$ & $F(717)=3.3[0.037]$ \\
\hline Systolic BP & $103.1 \pm 16.9$ & $108.5 \pm 17.4$ & $115.1 \pm 18.0$ & $F(738)=15.9[0.000]$ \\
\hline Diastolic BP & $69.4 \pm 8.6$ & $72.4 \pm 10.7$ & $76.1 \pm 11.4$ & $F(732)=13.0[0.000]$ \\
\hline
\end{tabular}

Bold typeface indicates significance at $p<0.05$.

ANOVA, analysis of variance; BP, blood pressure; K-10, Kessler-10; SOFAS, Social and Occupational Functioning Assessment Scale. 

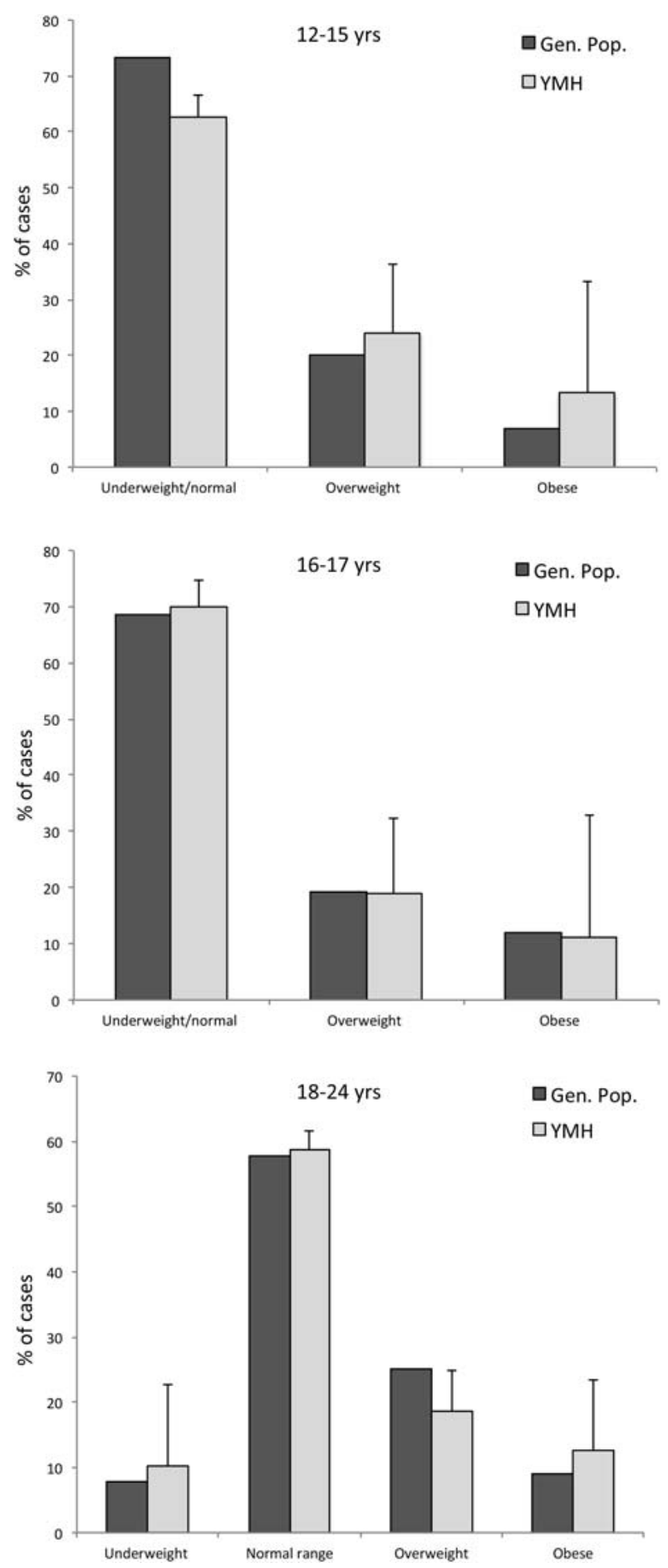

Figure 1 Proportion of youth mental health sample $(\mathrm{YMH})$ versus general population cases within body mass index categories for: (top) 12-15 years old; (middle) 1617 years old; and (bottom) 18-24 years old.

compared to $64.7 \%$ of those in the normal/underweight category. However, the models for each age group were not $\left(12-19\right.$ years: $\chi^{2}(1,62)=3.6$, $\mathrm{p}=0.072 ; 20-30$ years: $\left.\chi^{2}(1,67)=0.1, \mathrm{p}=0.100\right)$. For the 'any anti-depressant' versus 'not any anti-depressant' and 'any anti-psychotic' versus 'not any anti-psychotic' $\chi^{2}$ analyses, no models were significant.
Cardiovascular parameters

$\mathrm{BP}$ and sitting pulse rate (PR) was recorded in $73.5 \%$ $(739 / 1005)$ of cases. While there were no significant differences between females and males in diastolic BP or PR, mean systolic BP was higher in males (106.5 \pm 15.4 ; $116.0 \pm 20.0$, respectively; $\mathrm{t}=-6.87, \mathrm{df}=487.8, \mathrm{p}<0.001)$. In females, there were positive correlations between BMI and systolic $(\mathrm{r}=0.327, \mathrm{n}=456, \mathrm{p}<0.001)$ and diastolic $(\mathrm{r}=0.266, \mathrm{n}=450, \mathrm{p}<0.001)$ BP. In males, the same positive associations were present (BMI with systolic BP: $\mathrm{r}=0.214, \mathrm{n}=283, \mathrm{p}<0.001$; BMI with diastolic BP: $\mathrm{r}=0.246$, $\mathrm{n}=283, \mathrm{p}<0.001$ ). All of these correlations remained significant after controlling for age.

There was a significant MLR model for systolic BP-the overall model was highly significant $(F(6329)=8.5$, $\mathrm{p}<0.001$ ), explaining $13.8 \%$ of the variance (adjusted $\left.R^{2}=0.122\right)$, with three significant predictors: age $(\beta=0.149$, $\mathrm{p}<0.01)$, gender $(\beta=0.189, \mathrm{p}<0.005)$ and BMI $(\beta=0.227$, $\mathrm{p}<0.001)$. Thus, higher systolic BP was associated with increasing BMI, increasing age and being male. For diastolic BP, the overall model $(\mathrm{F}(6,324)=6.0, \mathrm{p}<0.001)$ explained $10.1 \%$ of the variance (adjusted $\mathrm{R}^{2}=0.084$ ) and included age $(\beta=0.213, p<0.001)$ and BMI $(\beta=0.161$, $\mathrm{p}<0.005)$ as significant predictors. The MLR model for PR was non-significant.

\section{Daily smoking rates}

Of the $\mathrm{N}=659$ cases with confirmed smoking status at the time of $\mathrm{BMI} /$ cardiovascular assessment, $29.7 \%$ $(\mathrm{N}=196)$ were daily smokers. Males were more likely to be daily smokers compared to females $(34.7 \%$ vs $26.5 \%$; $\left.\chi^{2}(659)=5.1, \mathrm{p}<0.05\right)$. As shown in table 1 , there was a significant difference among the three BMI-based groups with respect to the proportion of current daily smokers $\left(\chi^{2}(659)=10.7, \mathrm{p}<0.01\right)$ with the normal weight group have the highest proportion $(34.5 \%)$ compared to the other two groups $(22-24 \%)$. In terms of the proportion of smokers across age groups, there was a significant difference $\left(\chi^{2}(659)=6.0, \mathrm{p}<0.05\right)$ in the proportion of smokers in the three age groups: $12-17$ years, $24.7 \%$; 1819 years, $29.0 \%$ and; $20-30$ years, $34.4 \%$.

\section{Fasting glucose, CHOL, TG, HDLs and LDLs}

One-third (29.6\%; 298/1005; N=190 females) of cases with BMI data also had their fasting bloods collected. As shown in table 2, there were significant differences among the BMI categories for TGs and HDL, but no differences in the glucose or LDL levels. Compared to the other two groups, the overweight/obese group had the highest levels of the TGs and the lowest levels of HDL. There were significant differences between females and males in terms of their fasting glucose (males higher; $\mathrm{t}=-2.50, \mathrm{df}=296, \mathrm{p}<0.05$ ) and HDL (males lower; $\mathrm{t}=6.58, \mathrm{df}=209.1, \mathrm{p}<0.001$ ) but not in their total cholesterol, TGs and low-density lipoproteins. There was a significantly $\left(\chi^{2}=7.9, \mathrm{df}=298, \mathrm{p}=.005\right)$ higher proportion of males $(9.3 \%)$ compared to females $(2.1 \%)$ with a fasting glucose level $\geq 5.5 \mathrm{mmol} / \mathrm{L}$. There 
Table 2 Demographic and (fasting) blood parameter values for: (1) underweight; (2) normal; (3) overweight/obese cases aged $12-30$ years $(\mathrm{N}=298)$

\begin{tabular}{lclll}
\hline & Under $(\mathbf{n}=\mathbf{2 7})$ & Normal $(\mathbf{n}=\mathbf{1 7 4})$ & Over/obese $(\mathbf{n}=\mathbf{9 7})$ & $\begin{array}{l}\text { Significance test } \\
\chi^{2} \text { or ANOVA (df) [p] }\end{array}$ \\
\hline Female, \% $(n)$ & $74.1 \%(n=20)$ & $64.4 \%(n=112)$ & $59.8 \%(n=58)$ & $\chi^{2}(298)=1.9[0.381]$ \\
Age in years $($ mean \pm SD) & $19.4 \pm 3.2$ & $19.0 \pm 3.5$ & $19.6 \pm 3.8$ & $\mathrm{~F}(297)=1.1[0.346]$ \\
Glucose & $4.5 \pm 0.4$ & $4.5 \pm 0.5$ & $4.7 \pm 0.6$ & $\mathrm{~F}(297)=2.3[0.097]$ \\
Triglycerides & $1.0 \pm 0.4$ & $0.9 \pm 0.5$ & $1.3 \pm 0.8$ & $\mathrm{~F}(67.2)=6.9[0.002]$ \\
LDL & $2.6 \pm 0.8$ & $2.5 \pm 0.7$ & $2.7 \pm 0.8$ & $\mathrm{~F}(233)=2.1[0.119]$ \\
HDL & $1.5 \pm 0.3$ & $1.4 \pm 0.3$ & $1.2 \pm 0.3$ & $\mathrm{~F}(\mathbf{2 3 6})=5.5[0.005]$ \\
\hline
\end{tabular}

Bold typeface indicates significance at $p<0.05$.

ANOVA, analysis of variance; BP, blood pressure; HDL, high-density lipoprotein; LDL, low-density lipoprotein.

was no significant difference in the proportion of females versus males with high levels $(\geq 2.0)$ of TGs (6.5\% and $7.7 \%$, respectively). In terms of the lipoprotein thresholds, while the proportion of females $(4.0 \%)$ and males $(3.6 \%)$ with high $(>4.0)$ levels of LDL did not differ, there was a significantly $\left(\chi^{2}=32.2, \quad \mathrm{df}=237\right.$, $\mathrm{p}<0.001)$ higher proportion of males $(34.1 \%)$ compared to females $(5.9 \%)$ with low levels $(\leq 1.0)$ of HDL.

The relationship between $\mathrm{BMI}$ and fasting glucose levels was non-significant for both females $(r=0.102$, $\mathrm{n}=190, \mathrm{p}=0.16)$ and males $(\mathrm{r}=0.119, \mathrm{n}=108, \mathrm{p}=0.22)$. Of note, these associations (in each gender) remained nonsignificant when the cases with underweight BMI scores were excluded from the bivariate analyses. By contrast, for females there were significant correlations between BMI and all three CHOL variables: TG $(r=0.165, n=184$, $\mathrm{p}<0.05)$, LDL $(\mathrm{r}=0.169, \mathrm{n}=150, \mathrm{p}<0.05)$ and HDL $(\mathrm{r}=-0.268, \mathrm{n}=152, \mathrm{p}<0.001)$ levels. In males, only TG levels were correlated with BMI $(r=0.328, n=104$, $\mathrm{p}<0.01)$. Furthermore, all of these correlations remained significant when the underweight cases were removed from the analyses.

The MLR model for fasting glucose was found to be non-significant. For total cholesterol, the overall model $(\mathrm{F}(6,177)=2.2, \mathrm{p}<0.05)$ explained $7.1 \%$ of the variance (adjusted $\left.\mathrm{R}^{2}=0.038\right)$ and included age $(\beta=0.176, \mathrm{p}<0.05)$ and gender $(\beta=-0.175, \mathrm{p}<0.05)$ as significant predictors. For TGs, the overall model was at trend-level significance $(\mathrm{F}(6,177)=2.1, \mathrm{p}=0.056)$, explaining $6.9 \%$ of the variance (adjusted $\left.\mathrm{R}^{2}=0.036\right)$ and included only BMI $(\beta=0.221$, $\mathrm{p}<0.005)$ as a significant predictor. For LDL, the overall model $(\mathrm{F}(6,150)=2.1, \mathrm{p}<0.05)$ explained $10.2 \%$ of the variance (adjusted $\mathrm{R}^{2}=0.064$ ) and included only age $(\beta=0.221, p<0.01)$ as a significant predictor. For HDL, the overall model $(\mathrm{F}(6,154)=7.9, \mathrm{p}<0.001)$ explained $24.2 \%$ of the variance (adjusted $\mathrm{R}^{2}=0.212$ ) and included gender $\quad(\beta=-0.363, \quad p<0.001)$ and $\mathrm{BMI} \quad(\beta=-0.250$, $\mathrm{p}<0.001)$ as significant predictors.

\section{Developmental phenotypes and clinical stage}

More than three-quarters of the sample ( $\mathrm{N}=775$ cases) were classified according to our tripartite model of developmental psychopathology. Of these, just under $70 \%$ $(n=541)$ met criteria for the ANX-DEP subtype, $13.4 \%$ $(\mathrm{n}=104)$ met criteria for 'mania-fatigue/atypical depression' and $16.8 \% \quad(n=130)$ were in the 'developmentalpsychotic' category. Table 3 outlines the demographic, clinical and physical health aspects of these three subgroups. There was a significant difference in the gender ratio among the tripartite groups $(\mathrm{p}<0.001$; see

Table 3 Demographic, clinical and blood pressure values for tripartite categories: (1) ANX-DEP; (2) MAN-FAT; (3) DEV-PSY cases aged $12-30$ years $(\mathrm{N}=775)$

\begin{tabular}{|c|c|c|c|c|}
\hline & ANX-DEP $(n=541)$ & MAN-FAT $(n=104)$ & DEV-PSY $(n=130)$ & $\begin{array}{l}\text { Significance test } \\
\chi^{2} \text { or ANOVA (df) [p] }\end{array}$ \\
\hline Female, \% (n) & $67.1 \%(n=363)$ & $70.2 \%(n=73)$ & $40.0 \%(n=52)$ & $\chi^{2}(775)=35.7[0.000]$ \\
\hline Age in years (mean $\pm S D)$ & $19.0 \pm 3.3$ & $20.8 \pm 3.5$ & $18.8 \pm 4.0$ & $F(197.4)=11.9[0.000]$ \\
\hline $\mathrm{BMI}$ & $23.3 \pm 5.1$ & $23.6 \pm 4.3$ & $23.9 \pm 4.7$ & $F(260)=0.3[0.755]$ \\
\hline$\%$ underweight & $10.0 \%(n=54)$ & $3.8 \%(n=4)$ & $7.7 \%(n=10)$ & $\chi^{2}(775)=4.3[0.115]$ \\
\hline$\%$ overweight/obese & $32.2 \%(n=174)$ & $33.7 \%(n=35)$ & $40.8 \%(n=53)$ & $\chi^{2}(775)=3.5[0.176]$ \\
\hline SOFAS & $64.5 \pm 11.0$ & $64.2 \pm 13.6$ & $59.4 \pm 13.5$ & $F(153.1)=6.9[0.001]$ \\
\hline Distress (K-10 total) & $31.0 \pm 8.3$ & $30.9 \pm 8.7$ & $26.5 \pm 8.6$ & $F(698)=8.6[0.000]$ \\
\hline Current smoker, \% (n) & $27.3 \%$ & $33.3 \%$ & $29.5 \%$ & $\chi^{2}(525)=1.0[0.603]$ \\
\hline Pulse rate & $77.8 \pm 18.8$ & $76.3 \pm 16.3$ & $76.8 \pm 15.0$ & $F(568)=0.3[0.754]$ \\
\hline Systolic BP & $109.2 \pm 19.1$ & $112.0 \pm 15.0$ & $110.3 \pm 18.6$ & $F(583)=0.8[0.458]$ \\
\hline Diastolic BP & $73.5 \pm 10.8$ & $75.0 \pm 11.1$ & $74.5 \pm 12.2$ & $F(577)=0.8[0.433]$ \\
\hline
\end{tabular}


table 3), with the MAN-FAT group having the highest proportion $(70.2 \%)$ and the DEV-PSY the lowest proportion of females $(40.0 \%)$. While the MAN-FAT group was the oldest (20.8 \pm 3.5 years) and DEV-PSY the youngest (at 18.8 \pm 4.0 years), the latter also showed the lowest levels of socio-occupational function with the lowest levels of psychological distress (K-10) compared to the other two subgroups. Notably, there were no differences among the diagnostic subgroups groups in terms of mean BMI and $\mathrm{BP} / \mathrm{PR}$ (including after controlling for the potential effects of age and gender). This overall pattern remained in the subset of patients who also had their bloods taken $(\mathrm{N}=261)$. Of note, there were no significant differences among the subgroups in terms of their mean clinical bloods measures (ie, glucose, TGs, LDL and HDL; see table 4).

\section{DISCUSSION}

This report outlines the distribution of BMI $(n=1005)$, cardiovascular risk $(\mathrm{n}=739)$ and other metabolic characteristics $(n=298$; within a month of the BMI measurement) in young people presenting early in the course of common anxiety, mood or psychotic disorders. These data are critical to advancing our understanding of the developmental pathways to increased rates of premature ischaemic heart disease and the planning of cohort-based and individual clinical programmes to change those paths. While a third $(330 / 1005)$ of the young people are overweight or obese, this is not substantially different to the aged-matched general population in Australia and, surprisingly, there is no clear association (at least at this early stage of mental illhealth) between increasing BMI and raised fasting glucose. However, we did find a pattern of high TGs and low HDL levels in those who were overweight/obese, which is typically observed in this group. ${ }^{19}$ Furthermore, smoking emerges as a major risk factor with $30 \%$ of all participants smoking daily compared with $\sim 11 \%$ reported for this age-based cohort in Australia. ${ }^{39}$

While the general pattern of associations in this sample do show slowly increasing other cardiovascular and metabolic risks among males, as well as with increasing age and increasing social and occupational disability, the overall pattern strongly suggests the need for preventive interventions (other than smoking cessation) to be directed at the whole group rather than selected on the basis of individual risk profiling. This is consistent with the emerging fields of how best to modify those risks in other young people who are currently overweight or obese or have metabolic profiles that may be indicative of somewhat increased longer-term risk of poor cardiovascular health. ${ }^{19} 2840$

A common assumption in current mental health practice is that those at greatest risk of developing cardiovascular disease or metabolic disturbance do so as a consequence of weight gain that results from illnessdependent factors such as decreased activity levels, increased food intake or other medication dependent effects. The findings of a lack of correlation between BMI and fasting glucose in males and females are therefore worthy of further consideration. In younger participants, it may be consistent with the notion that at this stage of life, and of illness duration, raised glucose levels are due largely to unrelated genetic influences, as well as the fact that many of those with higher BMIs are not yet insulin resistant. This is a situation, however, that may change quickly if the mental disorder persists or

Table 4 Demographic, clinical and (fasting) blood parameter values for tripartite categories in cases aged 12-30 years $(\mathrm{N}=261)$

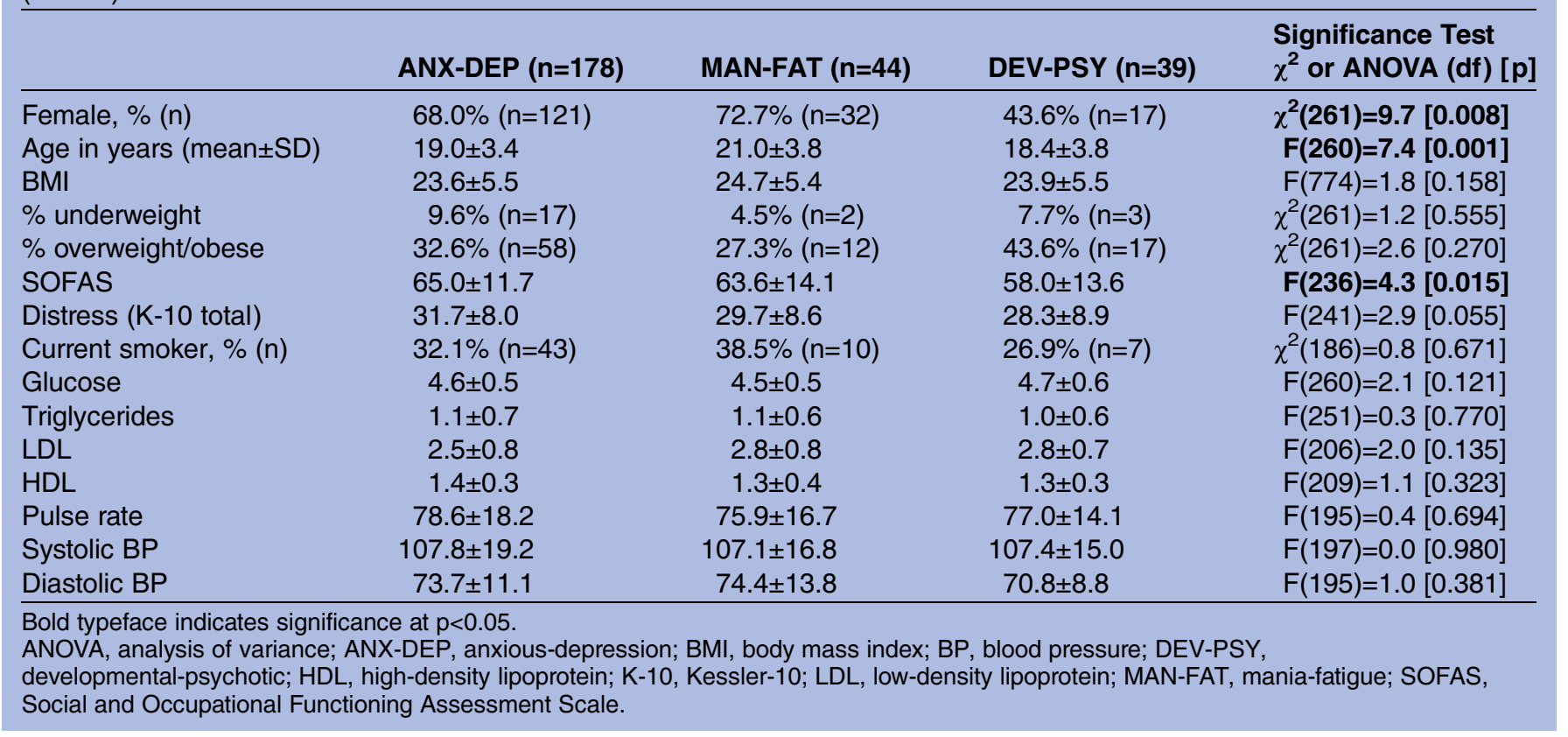


medications with adverse metabolic effects (eg, second generation antipsychotics, some antidepressants) are prescribed to treat the primary mental disorder or the person develops other comorbid behaviours such as increased food intake, lowered levels of physical activity or perturbed circadian rhythms.

From a developmental and diagnostic perspective, it is important to consider whether some individuals are at greater risk of gaining weight or developing other indicators of metabolic or cardiovascular risk as a direct consequence of their illness-type. For example, those with marked circadian disruption (as seen in atypical depression or bipolar disorder, here captured in the 'mania-fatigue' subtype, or as part of a psychotic disorder, here captured as 'developmental-psychotic') might be expected to be at particular risk of increased BMI and associated metabolic disturbance very early in their illness course. Within the limitations of this crosssectional study, however, we were not able to detect major differences in BMI or metabolic or cardiovascular risk on the basis of diagnostic-developmental subtype. However, those younger participants did appear to have somewhat lower risk, consistent with the notion that risk accumulates in association with illness progression, chronicity or concurrent treatments. Other limitations of the present study include: (1) a lack of a comparison group (eg, healthy individuals seeking care); (2) potential selection biases (eg, differences in those who decided to undergo blood tests vs those that did not); (3) generalisability (eg, these results may not be relevant to young people with mental health problems in other settings and/or countries). Future studies should aim to address these issues.

The findings reported here of relatively normal patterns of BMI and other metabolic and cardiovascular risk factors in this population are very different from those that are commonly reported in middle-aged persons receiving specialist care for psychotic or major mood disorders. This suggests that younger age and/or earlier stages of illness are likely to be key factors underlying such patterns. However, there is evidence of metabolic abnormalities and increased cardiovascular risk in young people with first episode psychotic attending early intervention or other specialised mental health services. ${ }^{3} 441$ Of note, a US study of 76 young, first episode psychosis (schizophrenia) patients attending an urban community mental health centre were found, at entry, to have comparable metabolic profiles to their community peers. ${ }^{42}$ However, over the course of the subsequent year, these patients had a significant worsening of cardiovascular risk factors (especially, smoking and obesity). In much of the early psychosis literature, the first year following onset has been described as the "critical period ${ }^{42-44}$ for the delivery of optimal interventions to prevent excess morbidity and early mortality. This concept has not been extended to include improved physical as well as mental health and other functional outcomes.

More recently, there have been major refinements to the concepts of prodromal and critical periods for early psychosis to include the more elaborated notion of clinical staging, thereby capturing a greater continuum of the journey from early symptoms to established illness ${ }^{11}$ Further, the concept has been broadened to include young people with emerging mood disorders. ${ }^{10} 45$ Within this framework, the greatest opportunities for modifying the course of illness, including physical health comorbidity, are extended to include a wider spectrum of earlier periods of disabling symptoms and the more obvious early periods of discrete disorder. A priority for early intervention research now is to evaluate whether group or individual-level interventions at these very early stages may help to reduce smoking rates or prevent the increased rates of being overweight or obese or of other specific metabolic complications that are common in those young people presenting for specialist mental healthcare.

Contributors EMS, DFH, SLN and IBH designed the study and wrote the protocol. DFH and IBH reviewed the literature; DFH and DW conducted the statistical analyses. EMS, DFH and IBH drafted the manuscript. EMS, DFH, BGW, JG and SLN were involved in study coordination, data collection and analyses. SLN and NG contributed to the study interpretation. All authors contributed to and have approved the final manuscript.

Funding This work was supported by National Health \& Medical Research Council (NHMRC) Program (No. 566529) and Centres of Research Excellence (No. 1061043) grants. Professor Naismith is supported by a NHMRC Clinical Research Fellowship (No. 402864) and Professor Hickie is supported by a NHMRC Senior Principal Research Fellowship (No. 1046899).

Competing interests EMS is the (unpaid) Clinical Director of headspace services at the BMRI and Deputy Director of St Vincent's Private Hospital Young Adult Mental Health Unit. She has received honoraria for educational seminars related to the clinical management of depressive disorders supported by Servier and Eli-Lilly pharmaceuticals. She has participated in a national advisory board for the antidepressant compound Pristiq,

manufactured by Pfizer. DFH has received honoraria for educational seminars from Janssen-Cilag and Eli Lilly. IBH has led a range of community-based and pharmaceutical industry-supported depression awareness and education and training programmes. He has led depression and other mental health research service evaluation or investigator-initiated research projects that have been supported by a variety of pharmaceutical partners. Servier and Pfizer support current investigator-initiated studies. He has received honoraria for his contributions to professional educational seminars related to depression, youth mental health and circadian-rhythms research. He has received travel support from Servier to attend scientific meetings related specifically to circadian-rhythm disorders.

Ethics approval The Human Research Ethics Committee of the University of Sydney approved this study.

Provenance and peer review Not commissioned; externally peer reviewed.

Data sharing statement No additional data are available.

Open Access This is an Open Access article distributed in accordance with the Creative Commons Attribution Non Commercial (CC BY-NC 4.0) license, which permits others to distribute, remix, adapt, build upon this work noncommercially, and license their derivative works on different terms, provided the original work is properly cited and the use is non-commercial. See: http:// creativecommons.org/licenses/by-nc/4.0/

\section{REFERENCES}

1. Lopez AD, Mathers CD, Ezzati M, et al. Global and regional burden of disease and risk factors, 2001: systematic analysis of population health data. Lancet 2006;367:1747-57. 
2. Gustavsson A, Svensson M, Jacobi F, et al. Cost of disorders of the brain in Europe 2010. Eur Neuropsychopharmacol 2011;21:718-79.

3. Bensenor IM, Brunoni AR, Pilan LA, et al. Cardiovascular risk factors in patients with first-episode psychosis in Sao Paulo, Brazil. Gen Hosp Psychiatry 2012;34:268-75.

4. Perez-Iglesias R, Martinez-Garcia O, Pardo-Garcia G, et al. Course of weight gain and metabolic abnormalities in first treated episode of psychosis: the first year is a critical period for development of cardiovascular risk factors. Int J Neuropsychopharmacol 2014:17:41-51.

5. Insel TR. The arrival of preemptive psychiatry. Early Interv Psychiatry 2007;1:5-6.

6. Insel TR. Translating scientific opportunity into public health impact: a strategic plan for research on mental illness. Arch Gen Psychiatry 2009:66:128-33.

7. Hickie IB, Scott EM, Hermens DF, et al. Applying clinical staging to young people who present for mental health care. Early Interv Psychiatry 2013;7:31-43.

8. Scott EM, Hermens DF, Glozier N, et al. Targeted primary care-based mental health services for young Australians. Med J Aust 2012;196:136-40.

9. McGorry PD, Yung AR, Pantelis C, et al. A clinical trials agenda for testing interventions in earlier stages of psychotic disorders. Med $\mathrm{J}$ Aust 2009;190(4 Suppl):S33-6.

10. Scott J, Leboyer M, Hickie I, et al. Clinical staging in psychiatry: a cross-cutting model of diagnosis with heuristic and practical value. Brit J Psychiatry 2013;202:243-5.

11. McGorry PD, Hickie IB, Yung AR, et al. Clinical staging of psychiatric disorders: a heuristic framework for choosing earlier, safer and more effective interventions. Aust $N Z J$ Psychiatry 2006;40:616-22.

12. Hickie IB, Groom GL, McGorry PD, et al. Australian mental health reform: time for real outcomes. Med J Aust 2005;182:401-6.

13. Huang RC, Stanley FJ, Beilin LJ. Childhood obesity in Australia remains a widespread health concern that warrants population-wide prevention programs. Med J Aust 2009;191:45-6.

14. Parikh NI, Hwang SJ, Larson MG, et al. Parental occurrence of premature cardiovascular disease predicts increased coronary artery and abdominal aortic calcification in the Framingham Offspring and Third Generation cohorts. Circulation 2007;116:1473-81.

15. Manzanares N, Monseny R, Ortega L, et al. Unhealthy lifestyle in early psychoses: the role of life stress and the hypothalamic-pituitary-adrenal axis. Psychoneuroendocrinology 2014;39:1-10.

16. Hennekens $\mathrm{CH}$, Hennekens AR, Hollar D, et al. Schizophrenia and increased risks of cardiovascular disease. Am Heart $J$ 2005:150:1115-21.

17. Marazziti D, Rutigliano G, Baroni S, et al. Metabolic syndrome and major depression. CNS Spectr 2014;19:293-304.

18. Goldstein $\mathrm{BI}$, Fagiolini A, Houck $\mathrm{P}$, et al. Cardiovascular disease and Metabolic syndrome and major depression hypertension among adults with bipolar I disorder in the United States. Bipolar Disord 2009:11:657-62.

19. Nadeau KJ, Maahs DM, Daniels SR, et al. Childhood obesity and cardiovascular disease: links and prevention strategies. Nature reviews. Cardiology 2011;8:513-25.

20. Cooper J, Mancuso SG, Borland R, et al. Tobacco smoking among people living with a psychotic illness: the second Australian survey of psychosis. Aust N Z J Psychiatry 2012;46:851-63.

21. Hickie IB, Scott J, McGorry PD. Clinical staging for mental disorders: a new development in diagnostic practice in mental health. Med $J$ Aust 2013;198:461-2.

22. Hickie IB, Scott J, Hermens DF, et al. Clinical classification in mental health at the cross-roads: which direction next? BMC Med 2013;11:125.

23. Hickie IB, Hermens DF, Naismith SL, et al. Evaluating differential developmental trajectories to adolescent-onset mood and psychotic disorders. BMC Psychiatry 2013;13:303.
24. Hamilton BA, Naismith SL, Scott EM, et al. Disability is already pronounced in young people with early stages of affective disorders: data from an early intervention service. J Affect Disord 2011;131:84-91.

25. Scott E, Naismith SL, Whitwell BG, et al. Delivering youth-specific mental health services: the advantages of a collaborative, multi-disciplinary system. Australas Psychiatry 2009;17:189-94.

26. Hermens DF, Scott EM, White D, et al. Frequent alcohol, nicotine or cannabis use is common in young persons presenting for mental healthcare: a cross-sectional study. BMJ Open 2013;3: e002229.

27. Genuth S, Alberti KG, Bennett P, et al. Follow-up report on the diagnosis of diabetes mellitus. Diabetes Care 2003;26:3160-7.

28. Yudkin JS, Montori VM. The epidemic of pre-diabetes: the medicine and the politics. BMJ 2014;349:94485.

29. Bombin I, Mayoral M, Castro-Fornieles J, et al. Neuropsychological evidence for abnormal neurodevelopment associated with early-onset psychoses. Psychol Med 2013;43:757-68.

30. Keshavan MS. Development, disease and degeneration in schizophrenia: a unitary pathophysiological model. J Psychiatr Res 1999;33:513-21.

31. Peralta V, de Jalon EG, Campos MS, et al. The meaning of childhood attention-deficit hyperactivity symptoms in patients with a first-episode of schizophrenia-spectrum psychosis. Schizophr Res 2011;126:28-35.

32. Piper M, Beneyto M, Burne TH, et al. The neurodevelopmental hypothesis of schizophrenia: convergent clues from epidemiology and neuropathology. Psychiatr Clin North Am 2012;35:571-84.

33. Benazzi F. Depression with DSM-IV atypical features: a marker for bipolar II disorder. Eur Arch Psychiatry Clin Neurosci 2000;250:53-5.

34. Marchand WR, Lee JN, Johnson S, et al. Differences in functional connectivity in major depression versus bipolar II depression. $J$ Affect Disord 2013;150:527-32.

35. Angst J, Gamma A, Benazzi F, et al. Atypical depressive syndromes in varying definitions. Eur Arch Psychiatry Clin Neurosci 2006;256:44-54.

36. Angst J, Gamma A, Bowden CL, et al. Diagnostic criteria for bipolarity based on an international sample of 5,635 patients with DSM-IV major depressive episodes. Eur Arch Psychiatry Clin Neurosci 2012;262:3-11.

37. Diler RS, Birmaher B, Axelson D, et al. Dimensional psychopathology in offspring of parents with bipolar disorder. Bipolar Disord 2011;13:670-8.

38. Australia Bureau of Statistics. National Health Survey 2007-08. Commonwealth Government, 2009.

39. Australian Institute of Health and Welfare. 2010 National Drug Strategy Household Survey report. Drug Statistics Series No. 25. Cat. no. PHE 145. Canberra, 2011.

40. Ho M, Garnett SP, Baur LA, et al. Impact of dietary and exercise interventions on weight change and metabolic outcomes in obese children and adolescents: a systematic review and meta-analysis of randomized trials. JAMA Pediatr 2013;167:759-68.

41. Curtis J, Henry C, Watkins A, et al. Metabolic abnormalities in an early psychosis service: a retrospective, naturalistic cross-sectional study. Early Interv Psychiatry 2011:5:108-14.

42. Srihari VH, Phutane VH, Ozkan B, et al. Cardiovascular mortality in schizophrenia: defining a critical period for prevention. Schizophr Res 2013;146:64-8.

43. McGorry PD, Killackey E, Yung A. Early intervention in psychosis: concepts, evidence and future directions. World Psychiatry 2008; 7:148-56.

44. Birchwood M, Todd P, Jackson C. Early intervention in psychosis. The critical period hypothesis. Br J Psychiatry Suppl 1998;172:53-9.

45. McGorry PD, Goldstone SD, Parker AG, et al. Cultures for mental health care of young people: an Australian blueprint for reform. Lancet Psychiatry 2014;1:559-68. 